\title{
POR UMA RECONSTRUÇÃO DA TRADIÇÃO DURKHEIMIANA
}

\section{Jayme Gomes Neto}

(D) https://orcid.org/0000-0003-1561-9001

Universidade Federal do Rio Grande do Sul (UFRGS), Rio Grande do Sul - RS, Brasil. Email: jaymegomesnt@gmail.com

DOI: $10.1590 / 3510413 / 2020$

\section{Introdução}

Ao longo da história da sociologia, é provável que poucas figuras tenham sido tão mal compreendidas, como parece ser o caso de Émile Durkheim. Alvo de inúmeras polêmicas e disputas interpretativas, seu nome foi associado aos rótulos mais diversos: do conservadorismo político ao materialismo histórico; do positivismo ao idealismo. Sendo assim, não é de estranhar que também seu legado tenha sido retomado em uma série de direçôes, ao longo da história da teoria sociológica. Em linhas bem gerais, é possível identificar ao menos três geraçôes de autores um tanto diferentes, que, de uma forma ou outra, deram continuidade ao pensamento do sociólogo francês:

(I) A primeira geração é, em parte, contemporânea ao próprio Durkheim e diz respeito àquele conjunto

Artigo recebido em: 25/06/2019

Aprovado em: 24/02/2020 de autores reunido em torno da L'année sociologique. Entram aí uma série de nomes, tais como Celestin Bouglé, Marcel Mauss, Henri Hubert, Robert Hertz, François Simiand, Paul Fauconnet, Maurice Halbwachs, entre outros que compóem a chamada "escola durkheimiana". Esse primeiro momento é, comparativamente falando, provavelmente o de maior coesão da tradição, dada a proximidade com o mestre e a própria unidade institucional da Revista supracitado

(II) A segunda geração é aquela que protagoniza a retomada das ideias durkheimianas num contexto de autonomização disciplinar da sociologia, com suas respectivas disputas internas. De um lado, teríamos a influência durkheimiana fortemente assimilada no interior do estruturalismo (Lévi-Strauss) e do funcionalismo (Parsons, Merton) e, de outro, sua presença se faria sentir majoritariamente em uma sociologia dos rituais da vida cotidiana (Goffman) 
e das interaçóes (Garfinkel) - embora, nesse último caso, talvez de maneira bem mais atenuada.

(III) Uma terceira geração de autores emerge em meio a grandes tentativas de reformulação das ideias durkheimianas, com vistas à promoção de novas sínteses teóricas, pretensamente mais englobantes. Nessa fase, o pensamento durkheimiano é não apenas expandido em direção a novos objetos, ou mesmo radicalizado em termos de alguns caminhos logicamente abertos no interior de seu esquema conceitual, mas reformulado a fim de dar conta de problemas, até então, majoritariamente alheios à escola durkheimiana, tais como o conflito, o trauma, a violência simbólica, a autorreferenciação dos sistemas, etc. Entram, neste cenário, herdeiros mais distantes, como Pierre Bourdieu e Niklas Luhmann, e herdeiros mais declarados, como Randall Collins e Jeffrey Alexander.

No presente artigo, a análise da tradição durkheimiana ${ }^{1}$ seguirá um itinerário de quatro passos. (1) Na primeira parte, mapearemos de maneira bastante condensada alguns dos desdobramentos mais significativos do legado de Durkheim para a teoria social do século XX, representados a partir de figuras como Lévi-Strauss, Radcliffe-Brown, Parsons, Merton, Goffman, Garfinkel, entre outros; (2) Feito isso, encaminharemos, a partir desse sobrevoo preliminar, a seguinte questáo: como devemos ler a chamada "tradição durkheimiana"? E, mais ainda: será possível, frente à multiplicidade de seus desdobramentos, compreendê-la como dotada de relativa coerência e inteligibilidade internas? (3) Diante de tais colocaçóes, argumentaremos que uma resposta adequada exigirá um movimento de síntese teórica fundado na releitura e nas articulaçóes de conceitos centrais à teoria do próprio Durkheim. (4) Por fim, concluiremos que tal movimento permite vislumbrar, ainda que em germe, uma nova inteligibilidade à sua tradição, compreendida, até então, como um conjunto de desenvolvimentos singulares e possivelmente contraditórios.

\section{Desdobramentos do Legado Durkheimiano}

Parte do modo de operação dos sociólogos consiste em saber construir e reconstruir as chamadas tradições intelectuais. Nesse sentido, é bastante comum que os grandes sociólogos sintam a necessidade de situar suas empreitadas mediante alguma tomada de posição quanto à sua própria filiação intelectual. No caso do pensamento durkheimiano, isso não é diferente. Alguns de seus herdeiros contemporâneos mais proeminentes, como Randall Collins e Jeffrey Alexander, tentaram, em diversos momentos, fornecer reconstruções sintéticas da história da tradição, as quais tomaremos, aqui, como ponto de partida. (Alexander, 1988a; 2005; Alexander \& Smith, 2005; Collins, [1991] 2009; 2005).

Um dos principais argumentos que estruturam a defesa desta tradição parece ser aquele segundo o qual os durkheimianos, ao contrário de outras linhagens teóricas no interior do século XX - tais como a teoria do conflito, a teoria das trocas ou o interacionismo simbólico -, teriam encontrado condiçôes de desenvolver contribuições significativas, tanto nos domínios das análises de estruturas macrossociais, quanto nos domínios das microinteraçóes de pequena escala. (Collins, 2009, p. 167). É em meio a esta distinção inicial - na qual começam a brotar, aliás, as primeiras dificuldades de reconstrução com vistas a uma unidade da tradição -, que iniciaremos a nossa reconstrução.

\section{Macro-durkheimianos: Estruturalismo e Funcionalismo}

Após a morte de Durkheim e de outros autores do círculo da L'Année Sociologique, à época da Primeira Guerra, a teoria durkheimiana passou por um período de declínio e só ganhou novo fôlego, em solo francês, algumas décadas mais tarde, em meio à marcha do pensamento estruturalista. Esse tipo de desdobramento, como se sabe, tendeu a privilegiar os aspectos mais idealistas do pensamento de Durkheim - principalmente suas reflexóes a respeito das representaçôes simbólicas, com suas respectivas dinâmicas internas, e suas consideraçôes sobre o pensamento classificatório -, tendo em vista uma abordagem estrutural da cultura e do pensamento humano. Esse movimento de retomada e expansão da herança durkheimiana numa perspectiva macrocultural encerra, como se sabe, algumas peculiaridades. 
A primeira consideração a esse respeito é de que os desdobramentos do pensamento durkheimiano são feitos aqui mediante os avanços da linguística saussuriana e, portanto, já sob novo terreno. No entanto, é igualmente importante notar, como faz Alexander, que o próprio Saussure parece acompanhar, em pontos centrais, o pensamento de Durkheim: "Ele define a linguagem como um fato social (un fait social) que emerge da consciência coletiva (conscience collective) da sociedade. [...]". (Alexander, 1988b, p. 4). ${ }^{2}$ Paralelamente a esse tipo de afirmação, é o próprio Lévi-Strauss quem nos lembra que "[...] linguistas como Saussure e Meillet reconheceram reiteradas vezes suas concordâncias e seus débitos com os ensinamentos de Durkheim" (Lévi-Strauss, [1945] 1995, p. 33). Na verdade, para além destas postulaçóes gerais, o fato é que toda uma série de proximidades entre os dois autores, tais como as homologias entre os signos saussurianos e as representaçóes coletivas durkheimianas, ou mesmo as respectivas assunçóes de uma autonomia dos sistemas simbólicos - proximidades estas, que constituíram objeto de estudo por parte de linguistas, como Ardener, Doroszewski e Godel (Alexander, 1988b, p. 4) -, sugerem o seguinte: mesmo em meio às inovações da linguística, o estruturalismo pareceu acompanhar, de maneira bastante próxima, algumas intuiçôes fundamentais de Durkheim.

O que estava em jogo, neste caso, era a assunção de uma autonomia dos sistemas representacionais com vistas à investigação de suas regras constitutivas. Foi a partir da aplicação dessa ideia - defendida por Durkheim no campo das representaçóes coletivas, e por Saussure, no campo dos signos -, que o próprio Lévi-Strauss pôde impulsionar seu programa de pesquisa. Em seu primeiro trabalho clássico, em 1949, o antropólogo reconhece abertamente o impulso da escola durkheimiana e encontra na figura de Mauss, sobrinho e principal discípulo do mestre francês, seu antecessor maior. (Lévi-Strauss, [1949] 1982, p. 92-108). Neste contexto, suas análises buscam investigar a gramática dos fatos sociais relativos ao parentesco, mobilizando, entre outras coisas, uma teoria das trocas e das alianças tal como preconizada por Mauss, em seu famoso Ensaio sobre a dádiva.
Mas, os desenvolvimentos da herança durkheimiana não param por aí. Mesmo quando, nas décadas seguintes, radicaliza seu estruturalismo em busca de mapear não mais determinados fatos sociais organizados sistematicamente, mas seus respectivos operadores lógicos inconscientes, Lévi-Strauss parece levar adiante - embora sem pleno reconhecimento - uma proposta já enunciada por Durkheim, mais de meio século antes: "investigar pela comparação de temas míticos, lendas, tradiçōes populares e línguas, de que modo as representaçóes sociais se atraem e se excluem, se fundem ou se distinguem umas das outras, etc." (Durkheim, [1895] 1937, p. xvii), com a finalidade de buscar suas leis transcendentais - algo que o próprio Durkheim havia designado, em outro contexto, como sendo as chamadas leis da "ideação coletiva”. (Durkheim, 1898, p. 45). Vale notar que esse paralelo entre os intelectualismos de Lévi-Strauss e Durkheim foi percebido por outros autores (Collins, 2009, p. 185; Jones, 2000, p. 69; Lukes, 1985, p. 437).

Uma segunda vertente de macroanálise no interior da tradição durkheimiana é a do funcionalismo, desenvolvida inicialmente no seio da antropologia britânica sob a tutela de Radcliffe-Brown e Meyer Fortes. Tal vertente, diferentemente do estruturalismo francês, acabou por privilegiar as estruturas morfológicas da sociedade, focando sua análise não necessariamente na dimensão simbólica das mesmas, mas nos aspectos funcionais dos fenômenos sociais situados em seu interior (Radcliffe-Brown, 1952; Alexander \& Smith, 2005 , p. 4). Sua referência mais imediata, neste caso, não são os textos sobre a religião - embora parte deles seja reabsorvida -, ou mesmo, sobre o pensamento classificatório, mas sim os trabalhos iniciais de Durkheim, notadamente Da Divisão do Trabalho Social (1893), As Regras do Método Sociológico (1895) e O Suicídio (1897). A noção de estrutura social passava, então, a ser compreendida num sentido mais materialista, como um conjunto de relações entre unidades empíricas determinadas. As diferenças em relação ao estruturalismo parecem ficar claras, por exemplo, em uma carta de Radcliffe-Brown endereçada a Lévi-Strauss:

Eu uso o termo 'estrutura' em um sentido tão diferente do seu, que fazer uma discussão nesse 
sentido dificilmente seria algo proveitoso. Enquanto para você a estrutura social não tem nada a ver com a realidade, mas com modelos construídos, eu a considero uma realidade [empírica]. (RadcliffeBrown apud Murdock, 1953, p. 109).

Não demorou até que esse tipo de interpretação chegasse à teoria sociológica. Ainda durante os anos 1930, um grupo de estudantes liderado por Robert Merton acabou por direcionar suas atençóes à obra de Radcliffe-Brown (Maryanski \& Turner, 1991, p. 112). Nesse caso, não era apenas uma interpretação mais materialista da noção de estrutura que parecia ganhar peso - em contraposição ao sentido mais idealista atribuído pelo estruturalismo francês -, mas a própria noção de função, que, a partir de então, passaria a ser desenvolvida de maneira original do outro lado do Atlântico. Nos anos seguintes, como se sabe, Merton (1949) desenvolve sua famosa distinção entre "funções latentes" e "funções manifestas", tendo como referência de fundo Da Divisão do Trabalho Social, livro considerado por ele como a "grande obra de Durkheim" e o "primeiro clássico da sociologia" (Merton, 1934; 1994).

Ainda na esteira do funcionalismo estrutural - em que se pressupóe não apenas a assunção de determinadas estruturas fixas a serem tomadas como ponto de referência, mas a própria ideia de uma ordem estrutural -, Merton pôde desenvolver, com base no famoso conceito de anomia, uma teoria das disfunçóes e do desvio social, compreendido agora em termos de uma "[...] dissociação entre as aspiraçóes culturalmente prescritas e os modos socialmente estruturados de realização dessas aspiraçóes" (Merton, 1968, p. 188). A nomenclatura de Merton - em que o ritualismo é compreendido como um tipo específico de comportamento desviante - não deixa dúvidas quanto ao tipo de filiação em jogo: trata-se do Durkheim anterior a As Formas Elementares da Vida Religiosa. Um tipo de filiação que, como bem apontam Neil Smelser e Stephen Warner (1976, p. 180), é também metodológica, e não apenas temática ou conceitual. Tal como o Durkheim de O Suicídio, Merton parece trabalhar com um tipo de teoria de "médio alcance", no qual as explicaçóes sociológicas não apenas se contrapóem àquelas de tipo biológico e psicológico, mas o fazem recorrendo a estatísticas comportamentais e hipóteses interpretativas em que figura, por trás de conceitos menos genéricos, aquele relativo à integração social.

Paralelamente ao funcionalismo estrutural de Merton, Talcott Parsons, seu ex-professor, desenvolveu uma segunda vertente do funcionalismo, de tipo normativo, aparentemente mais adequada à economia da obra durkheimiana. Nesse contexto, Parsons não apenas punha em jogo uma certa releitura original da obra inicial de Durkheim, na qual dava atenção aos problemas da integração e dos chamados "elementos não contratuais do contrato” - leitura que, aliás, acabaria por ser rotinizada nas décadas seguintes - mas considerava também aspectos importantes dos textos de maturidade do autor, principalmente aqueles relacionados aos temas da educação moral, da “introjeção" normativa (em que Parsons aproximaria, posteriormente, Durkheim e Freud) e da sacralidade dos símbolos coletivos. Ao final de seu famoso A Estrutura da Ação Social (1937), Parsons aliava Durkheim à sua proposta de uma teoria "voluntarista" da ação, e chegava a uma espécie de "estruturalismo normativo" como proposta ou programa de investigação (Alexander, 1987, p. 28). Tal como Durkheim, em seu famoso texto sobre as representaçóes (1898), e, posteriormente, Lévi-Strauss, Parsons parecia levar adiante, neste contexto, a proposta de investigação de uma gramática representacional no interior da coletividade: haveria, no fim das contas, uma estrutura de representações específicas (os valores) passível de tradução normativa em termos de uma diversidade de cursos de ação, a qual caberia investigar como sistema.

Embora tal investigação tenha levado, nas décadas seguintes, a um tipo de teoria dos sistemas que, por vezes, privilegiou o primeiro Durkheim, com suas contribuiçóes a uma teoria da diferenciação e da integração sociais (ver, por exemplo, Parsons, 1960), o Durkheim mais culturalista, da última fase, nâo foi completamente neutralizado. Edward Tiryakian, um ex-aluno de Parsons, mostra de maneira contundente, aliás, como os últimos trabalhos de seu antigo professor, nos anos 1970, são marcados pela releitura sistemática de As Formas Elementares da Vida Religiosa, livro que passa a ser compreendido por ele como fornecendo as principais chaves para o 
seu próprio projeto de uma investigação geral sobre a teoria da ação e da "condição humana" (Tiryakian, 2000, p. 76-81).

Tendo em mente este tipo de ambivalência, não é de espantar que entre os diversos alunos, seguidores e colaboradores de Parsons, a herança durkheimiana tenha sido levada adiante de maneira igualmente ambivalente. Nesse caso, teríamos, de um lado, uma série de abordagens macrossociais focadas nos processos de diferenciação sistêmica, com suas disfunções e suas eventuais (re)construções de solidariedades, suas generalizaçóes valorativas e suas complexificações normativas - algo que seria levado adiante por nomes como Marion Levi, Neil Smelser, Shmuel Eisenstadt e que encontraria seu apogeu nas análises de autores como Niklas Luhmann. De outro lado, teríamos a tentativa de incorporar os aspectos culturalistas e simbólicos da obra de Durkheim ao campo dos sistemas sociais modernos, por meio do enfoque de suas práticas rituais, seus esquemas classificatórios e seus elementos sacralizados. Entram aí, por exemplo, as análises sobre a "religião civil", sobre a sacralidade dos "centros" em contraposição ao caráter profano das "periferias" sistêmicas, bem como sobre o caráter performático e a dimensão efervescente de suas vidas políticas - temas que foram levados adiante por autores como Robert Bellah, Edward Shils e Edward Tiryakian e, posteriormente, desenvolvidos por nomes como Jeffrey Alexander.

\section{Micro-durkheimianos: Rituais e Interação}

Embora tenha dado enfoque às chamadas estruturas sociais, tentando mostrar seus respectivos vínculos constitutivos com determinados regimes de consciência - por meio de conceitos como os de solidariedade mecânica e orgânica, por exemplo -, Durkheim se coloca um tipo de problema um tanto diferente, a partir do final dos anos 1890: como conceber, do ponto de vista do indivíduo, a passagem entre estruturas sociais e as chamadas representaçóes coletivas? Parte da resposta, tal como formulada em sua última grande obra, passava pela elaboração de uma teoria dos rituais sociais. Tratava-se daqueles momentos de interação face a face marcados pela atenção num foco comum, e nos quais os interesses individuais mais imediatos seriam deixados de lado em prol de uma performance coletivamente orientada - dada por meio de movimentos, sons, manipulação de emblemas e símbolos. Essas interaçôes, marcadas pela alta densidade social e capazes de canalizar as energias emocionais de seus participantes, constituiriam, então, um modo adequado de expressão - mas, também, de reatualização e recriação - dos valores e crenças coletivas. Eis, entáo, um modo possivelmente adequado de passagem - de mão dupla - entre as estruturas sociais mais gerais e as representaçóes mentais. (Durkheim, 1912, p. 240; 1914, p. 330-31).

Como bem apontou Randall Collins ([1991] 2009 , p. 176), esse modo de colocar a questão acabou por fornecer à tradiçáo durkheimiana um instrumental poderoso para que ela se voltasse não apenas para as chamadas macroestruturas sociais, mas, sobretudo, para microinteraçóes e os rituais da vida cotidiana. É frente a esse tipo de consideração, aliás, que podemos compreender a supramencionada alocação de autores como Erving Goffman e o próprio Collins - seu pretenso herdeiro -, no interior da tradição de Durkheim. ${ }^{3}$

A aproximação entre Goffman e o pensamento durkheimiano é geralmente associada à influência exercida pela figura de Lloyd Warner, seu professor na Universidade de Chicago e, também, seu orientador de tese (Alexander, 1987, p. 231; Collins, [1991] 2009, p. 186; Treviño, 2003, p. 4). Warner fora inicialmente um australianista fortemente impressionado pelo trabalho de Durkheim sobre o totemismo. Durante os anos de 1940 e 1950, ele se esforçou em retomar o projeto durkheimiano, principalmente os aspectos rituais de sua teoria, no sentido de aplicá-la às sociedades industriais modernas. Em suas pesquisas mais localizadas sobre comunidades, tal como nas mais amplas sobre os mercados econômicos e as classes, Warner tratou de analisar as modernas sociedades estratificadas em termos de seus elementos rituais: o dia do trabalho, as paradas militares, o dia de Ação de Graças, o Natal e uma série de outros cerimoniais importantes da vida moderna foram compreendidos sob essa chave. Desse modo, Warner não apenas reforçava as teses durkheimianas quanto à criação de comunidades morais mediante performances e manipulações rituais, como também as expandia. Se, por um lado, os rituais 
colocavam em jogo símbolos e práticas capazes de criar laços de solidariedade, por outro, faziam-no de maneira a classificar e hierarquizar os próprios objetos sociais (emblemas, pessoas, grupos). Esse tipo de percepção acabava por complementar, do ponto de vista de seus aspectos culturais, as antigas análises sobre a estratificação social - compreendida, agora, como fenômeno eminentemente multidimensional (Collins, [1991] 2009, p. 188).

Nos anos seguintes, foi Erving Goffman quem aprofundou a intuição de Warner - que também era a de Durkheim - de que as análises rituais poderiam servir para compreendermos as sociedades industriais. Ele buscou ampliar o escopo de aplicação do conceito, de modo a compreender não apenas aqueles grandes cerimoniais da sociedade moderna, mas também uma série de interaçóes da vida cotidiana nas quais os elementos ritualísticos passariam, muitas vezes, despercebidos, ou seriam, até mesmo, inconscientes. Em seu primeiro grande trabalho, Goffman (1959) expandiu a análise durkheimiana dos rituais face a face, mediante a utilização de uma série de metáforas dramatúrgicas. Por meio da distinção entre os conceitos de "palco" e "bastidores", o autor pretendeu mostrar um tipo de operação ritual no qual os "atores" repetidamente desempenhavam "papéis" e manipulavam elementos do "cenário", de modo a constituir "fachadas" sociais. Nesse caso, embora a análise goffmaniana tenha tomado como ponto de partida a apresentação do self e, portanto, focado em aspectos subjetivos do processo ritual, é necessário notar, como faz Collins, que, a despeito dessa mudança de nível analítico, "a estrutura social, para Goffman, vem [ainda] em primeiro lugar" (Collins, [1991] 2009, p. 233). Frederic Keck, um conhecido intérprete da obra de Lévi-Strauss, chega a falar em uma "abordagem estruturalista" em Goffman, segundo a qual a metáfora dramatúrgica cederia lugar a uma compreensão das interaçóes em termos da manipulação de signos rituais - cujo valor seria dado não de maneira substancial, mas em termos de suas relações diferenciais e opositivas no interior de uma gramática das práticas. (Keck, 2012, p. 483-5).

Seja como for, o deslocamento analítico promovido por Goffman não deixava de ter por base também uma tese durkheimiana - reconhecida nominalmente por ele, diversas vezes ([1959] 1975, p. 69; [1967] 2011, p. 51, 74-5) -, a saber, a de que a personalidade humana, nas sociedades modernas, torna-se um objeto sagrado, alvo de culto ritual. Seguindo esse caminho, Goffman tomou como um exemplo privilegiado de análise os chamados "rituais de deferência", dados no interior de nossa vida cotidiana. Ele mostrava, nesse contexto, como uma grande parte de nossos intercâmbios sociais seria permeada por pequenos rituais de polidez nos quais reconheceríamos uma dignidade a nosso interlocutor e, nesse mesmo processo, adquiriríamos certo status social, na medida em que seríamos considerados sujeitos sociais aptos e conhecedores dos procedimentos e normas do ritual. Seguindo também, de maneira explícita, a famosa distinção durkheimiana entre ritos positivos e negativos, Goffman (1971, p. 62) pretendeu mostrar ainda como essas operaçóes seriam não apenas confirmadas por meio de uma série de respostas positivas e de "intercâmbios de suporte", mas corrigidas e "reparadas", no caso de algum desvio ou mesmo eventual ruptura, por uma série de outros mecanismos rituais (Goffman, 1971, caps. 2 e 3).

Ao desenvolver suas análises sobre o culto do eu e os modernos rituais da vida cotidiana, Goffman percebeu - tal como fizeram Durkheim e Warner, em um nível mais macroestrutural - que os rituais classificavam hierarquicamente seus objetos. No caso desses pequenos rituais, Goffman foi mais longe, ao insistir que a classificação e a hierarquização de objetos não eram apenas um dado da atividade ritual. Antes disso, os rituais eram armas simbólicas que os sujeitos, muitas vezes, utilizavam nos jogos de relaçóes sociais, fosse para estabelecer e reafirmar contatos sociais interessantes, fosse para envergonhar ou deslegitimar seus adversários. Esses insights, como se sabe, foram mais tarde levados adiante, por sociólogos como Basil Bernstein - que trabalhou os códigos linguísticos entre as diferentes classes sociais -, e, principalmente, Randall Collins. Utilizando-se de conceitos, como os de "capital ritual" e "meios de produção emocional”, Collins tentou fornecer à análise dos microrrituais um instrumental conceitual capaz de lidar mais adequadamente com o fenômeno da estratificação. (Collins, [1991] 2009, p. 191-203). Em verdade, Collins tem trabalhado, nos últimos 
anos, na tentativa ambiciosa de expandir as análises microrrituais e reconectá-las ao nível macro, por meio de uma teoria das "cadeias de interação ritual", que, segundo ele, sintetizaria, no interior da tradição durkheimiana, as contribuiçôes mais fundamentais da teoria do conflito e do interacionismo simbólico (Collins, 2004).

Entretanto, a linhagem goffmaniana não é a única dentre as abordagens microssociológicas que pretendeu levar adiante a tradição de Durkheim. Nesse contexto, vale notar que autores como Richard Hilbert (1991) e Anne Rawls (2000) defenderam, de maneira persuasiva, a existência de um outro tipo de continuidade, notadamente, a da sociologia durkheimiana e a etnometodologia de Harold Garfinkel. Embora a tradição etnometodológica tenha encontrado certa dificuldade em estabelecer vinculações teóricas com outras tradições, o próprio Garfinkel - de maneira um tanto surpreendente, aliás - defendeu, em seus textos mais tardios, uma filiação explícita ao mestre francês:

compreendida, de maneira correta [...], a etnometodologia é herdeira da tradição durkheimiana negligenciada [pela maioria dos sociólogos profissionais]. Ela tem trabalhado os aforismos de Durkheim como alternativas ao mesmo tempo inescapáveis e singularmente incomensuráveis que acompanham os ensinamentos canônicos da sociologia mundial. (Garfinkel, 2002, p. 94).

Dentre os "aforismos" de Durkheim, incessantemente trabalhados pela etnometodologia, talvez o mais fundamental, aos olhos de Garfinkel, seja aquele enunciado nas Regras do Método, a respeito da realidade empírico-fenomênica dos fatos sociais, a partir do que Durkheim "pôde então dotar a disciplina de uma matéria única e distinta” (Garfinkel, 2002, p. 93). A recuperação desse tipo de afirmaçáo, como bem apontou Hilbert, concerne à aposta, por parte dos etnometodólogos, na emergência de uma realidade (social) sui generis capaz de autorregulação (Hilbert, 1991, p. 342-3). Nesse caso, não apenas os problemas relativos à ordem social tornam-se necessariamente problemas empírico-práticos - no que os etnometodológos se opóem ao durkheimianismo de Parsons -, como a própria ordem cognitiva só pode aparecer como resultado dessa realidade emergente. Segundo Garfinkel (2002, p. 93) e, principalmente, Rawls (1996; 2000; 2004), sua discípula, essa intuição inicial de Durkheim seria corroborada em seu último trabalho, As Formas Elementares da Vida Religiosa - fazendo com que, aos olhos deles, a própria obra de Durkheim ganhasse coerência e unidade. Para tais autores, ao mostrar que até mesmo as categorias mais fundamentais de nosso pensamento - tais como tempo, espaço, causa, substância, etc. - seriam incompreensíveis sem um conjunto de interaçóes empíricas (os chamados rituais coletivos), Durkheim fornecia uma defesa, ao mesmo tempo, ambiciosa e radical do suposto etnometodológico segundo o qual a cognição seria fruto de uma experiência sui generis, eminentemente social.

Para além deste tipo de leitura - que encontra em Durkheim seus pressupostos analíticos fundamentais -, vale igualmente notar que Garfinkel retomou teses durkheimianas mais pontuais em suas análises empíricas. Quando fala sobre a "indexabilidade" dos conceitos e os vários mecanismos de interpretação ad hoc, a fim de mostrar a falta de fundamentação cognitiva da interação - cujo perigo constante seria o da "regressão ao infinito" na busca de definiçóes semânticas claramente estabelecidas-, Garfinkel repóe em circulação a tese da solidariedade ritual como fundamento da experiência ordenada do mundo. Collins ([1991] 2009, p. 242), numa observação perspicaz, lembra ainda que este tipo de argumento é também estruturalmente semelhante àquele mobilizado por Durkheim, em relação aos "elementos não contratuais do contrato": para Garfinkel, como para Durkheim, a manutenção de uma ordem nas interaçóes e nas expectativas não ocorre por conta de fatores racionais; no fundo de toda ordenação, existe um elemento emocional, que Durkheim encontra na solidariedade pré-contratual, enquanto Garfinkel o encontra na simples recusa da quebra de interação.

\section{A Questão da "tradiçáo durkheimiana"}

Dissemos, anteriormente, que a "tradição durkheimiana", tomada de maneira ampla, poderia remeter a três geraçóes mais ou menos esparsas de 
autores. A primeira geração, protagonizada pelos autores do círculo da L'année sociologique, teria sido, por razões ao mesmo tempo históricas e institucionais, aquela que comparativamente chegou mais próxima de uma unidade interna - o que não significa que não houvesse divergências e tensóes latentes em seu interior. Ao mesmo tempo - e talvez pelo mesmo conjunto de razóes -, ela parece ter sido, dentre todas as geraçóes, aquela que foi mais bem compreendida enquanto um grupo dotado de identidade, tendo sido alvo de alguns estudos bastante cuidadosos no interior da literatura especializada. ${ }^{4}$

Dito isto, parece ficar claro que o problema da "tradição durkheimiana", enquanto dotada de uma possível unidade e coerência, só aparece efetivamente como um problema, na "segunda geração" deste conjunto de autores; ou seja, quando as contribuiçóes de Durkheim encontram o solo de uma disciplina já autonomizada e uma pluralidade relativamente grande de perspectivas. Neste momento, autores tão divergentes, quanto Lévi-Strauss, Parsons, Merton, Goffman e Garfinkel, alegaram, todos eles, ter desenvolvido suas teorias, e até mesmo suas pesquisas empíricas, com base em uma suposta herança do mestre francês. Mas, se a figura de Durkheim é alocada aqui e ali, por diferentes abordagens, como tendo um lugar de honra em várias delas, essa alocação parece indicar a realização de reconstruçôes bastante seletivas. Isto é, reconstruções que mobilizariam vários Durkheims: o da morfologia social, o dos rituais, o das classificaçóes simbólicas, o da solidariedade e das normas pré-contratuais, e assim por diante. Esse tipo de colocação sugere, certamente, um problema já clássico na literatura especializada a respeito da possível unidade do pensamento do sociólogo francês.

No interior dos estudos durkheimianos, ao menos desde Parsons, diversos intérpretes se debateram com a questão da unidade do pensamento durkheimiano. Warren Schmaus (1994, p. 12-17), um de seus grandes intérpretes, assinalou que parece haver aí uma tensão entre: (a) as leituras feitas por aqueles que buscaram incorporar o pensamento de Durkheim com vistas à resolução de determinados problemas teóricos e empíricos no interior da agenda de pesquisa da sociologia - como foi o caso dos autores mencionados em nossa reconstrução, inclusive, mais recentemente, Alexander e Collins; e (b) as leituras feitas por autores que tentaram fornecer uma compreensão mais contextual à obra de Durkheim, feitas, na maioria das vezes, por comentadores especializados. De um lado, o foco parece recair sobre as rupturas e as descontinuidades do pensamento de Durkheim; de outro, na aposta de se poder encontrar uma coerência no interior do desenvolvimento de seus esquemas conceituais. ${ }^{5}$

Ora, esse aparente dilema, se bem compreendido, não constitui apenas um problema de interpretação, mas a própria questão da tradição. Como vimos, a alegação de pertencimento à tradição de Durkheim só parece fazer sentido, ao menos do ponto de vista dos autores que analisamos, na medida em que se compreendem determinadas operaçóes de seleção no interior da obra do sociólogo francês, nas quais alguns aspectos são privilegiados em detrimento de outros. Divisóes entre micro e macro, agência e estrutura, pensamento conceitual e performance ritual, ordem normativa e ordem factual são fundamentais nesse processo de releitura. No entanto, se os vários Durkheims retomados forem, de fato, contraditórios - como parecem sugerir, às vezes, os desenvolvimentos das obras de Lévi-Strauss, Radcliffe-Brown, Parsons, Merton Goffman e Garfinkel -, então a própria ideia de uma tradição não passaria de ficção. Neste caso, não haveria nada capaz de ligar todos esses desenvolvimentos, a não ser o nome de Durkheim, cujo significado seria tomado em sentidos diferentes por cada um de seus pretensos herdeiros. Paralelamente a isso, entretanto, há o fato de que a tese aparentemente mais aceita entre os comentadores atuais parece ser justamente a contrária: isto é, a de que seria possível encontrar uma unidade no pensamento de Durkheim. Nesse caso, a saída mais óbvia seria insistir que se tais intérpretes estiverem certos, então as afirmaçôes dos teóricos supramencionados - os herdeiros da segunda geração - provavelmente incorreriam em erros de leitura.

Frente a esse aparente dilema, acreditamos, contudo, que o verdadeiro problema da tradição pode ser formulado de maneira mais promissora: será possível encontrar, por trás dos desenvolvimentos aparentemente contraditórios de autores como Lévi-Strauss, Parsons, Goffman e outros algum tipo de esquema conceitual dotado de possibilidades lógicas de desenvolvimento a tal ponto abertas, que possamos ainda alocá-los no interior de uma herança intelectual dotada de coerência 
e unidade? Consideramos que, do ponto de vista da reconstrução da história da tradição, esta talvez seja a pergunta mais importante a ser feita. Afinal, no caso de uma resposta positiva, poder-se-ia entăo encontrar algum tipo de compatibilizaçáo - ou, até mesmo, as condiçōes intelectuais de uma possível superação - das aparentes tensóes entre: (1) a unidade proposta por boa parte dos comentadores mais autorizados ao nível do corpus durkheimiano; e (2) a aparente fragmentação das demandas de filiação, por parte de alguns dos sociólogos mais importantes do século XX.

\section{Síntese Teórica e Reconstruçáo da Matriz Durkheimiana}

Nos pontos anteriores, tivemos por base uma rápida leitura que buscou sintetizar algumas das incorporaçôes do pensamento durkheimiano na obra de importantes sociólogos do século XX. Vimos como as várias alegaçóes no interior desta literatura, a despeito de sua possível pertinência, pareciam insuficientes quanto ao reconhecimento de uma possível unidade no pensamento e, de certo modo, na própria tradição de Durkheim. Mas, uma vez colocada a questão - e justamente na medida em que ela aparece, nesse contexto, como uma espécie de problema mal resolvido -, fica claro que uma possível resolução, caso exista, deverá ser encontrada em outro lugar. Desse modo, parece pertinente voltar à literatura especializada que tratou de analisar a obra durkheimiana de maneira contextual, mapeando seu desenvolvimento e encontrando aí certa coerência e unidade programáticas. Nosso ponto de partida segue de perto tal literatura: em princípio, acreditamos que seja possível encontrar, por via reconstrutiva, uma unidade no pensamento do autor, donde se segue que também seria possível encontrar, em princípio, alguma unidade no interior de sua tradição. Neste sentido, nossa proposta não se distancia daquilo que já é praticado, embora em outro nível e com outros objetivos, por intérpretes contemporâneos do pensamento de Durkheim.

Mais precisamente, propomos que se esta unidade do esquema teórico-conceitual deve ser entendida como sendo capaz de remeter a uma multiplicidade de desdobramentos na história da teoria sociológica - que, na maioria das vezes, aliás, não constitui o alvo de preocupaçáo dos comentadores especializados na obra de Durkheim -, entáo ela só pode ser compreendido na qualidade de um esquema teórico multidimensional. No interior de sua unidade semântica, deve haver um conjunto mínimo de tensóes, ainda que em equilíbrio, que permitam, ao menos virtualmente, uma série de desdobramentos possíveis. Esse arranjo delicado (mas possível) entre elementos diferenciais no interior de uma mesma unidade parece poder ser encontrado justamente na articulaçáo entre uma sociologia interessada na morfologia social (supostamente protagonizada pelo jovem Durkheim) e uma sociologia voltada às representaçóes coletivas (supostamente delineada pelo Durkheim em seu período de maturidade). Somente tendo em vista essa articulaçáo central entre elementos materiais, ideais e simbólicos é que teremos condiçōes de identificar as variantes internas que levaram a apropriaçôes diferenciais do legado durkheimiano.

Na próxima subseção, delinearemos um pouco melhor o que motivou a referida passagem entre uma reflexão morfológica e uma reflexão representacional. Num segundo aprofundamento, focaremos em um conceito específico, o de "representaçôes coletivas", compreendido como peça central da movimentaçấo durkheimiana em direçẫo a uma teoria multidimensional. Vale notar que ao nos debruçarmos sobre este conceito, estamos em consonância com boa parte da literatura especializada, que o considera um conceito-chave do pensamento de Durkheim. ${ }^{6}$ Neste contexto, parece-nos que se algum sentido de unidade no interior de sua herança intelectual puder ser encontrado, é provável que tal unidade gire em torno da aceitação - explícita ou implícita, parcial ou integral - do próprio conceito de representação, com suas respectivas possibilidades lógicas de desenvolvimento e suas relaçôes com a antiga morfologia social. Como veremos, uma compreensão aprofundada deste conceito nos permitirá reconstruir, de maneira mais detalhada, os vínculos constitutivos entre o pensamento de Durkheim e o de alguns teóricos supramencionados, como Lévi-Strauss, Parsons, Goffman e outros.

\section{Da morfologia social às representaçóes coletivas}

Em seu primeiro trabalho empírico, $A$ Divisão do Trabalho Social (1893), a preocupaçáo central de Durkheim, tal como a de inúmeros outros sociólogos 
de sua época, voltava-se para a passagem das sociedades ditas "primitivas" às chamadas sociedades "modernas". Mais especificamente, Durkheim estava preocupado com o processo de crescente especialização das funções sociais na modernidade - funções jurídica, econômica, política, moral, científica, etc. - e se perguntava como, num tal registro, era possível pensar a manutenção de uma possível integração social. Em outras palavras, por quais razóes, numa sociedade marcada pela individualização e pela especialização crescentes - dos homens e das funções -, os vínculos sociais e os sistemas de relaçóes simplesmente não se desmanchavam?

Parte da resposta de Durkheim, como se sabe, consistia, ao menos num primeiro momento, em mostrar que os vínculos de solidariedade na modernidade não desapareciam, mas mudavam de tipo - ou ao menos mudavam majoritariamente. Assim, seu argumento consistia em mostrar como e em que medida os vínculos presentes nas sociedades especializadas diferiam em relação àqueles estabelecidos nas sociedades com baixo grau de especialização. Num caso, a base fundamental desses vínculos de solidariedade residia no caráter de complementaridade das funções; no outro, em sua similaridade. Durkheim encontrava, então, nesse primeiro momento de sua obra, dois modos privilegiados de ligação e de relação entre os homens, a serem expressos pelos conceitos de "solidariedade orgânica" e "solidariedade mecânica". O primeiro modo de relação era caracterizado pela crescente autonomia individual e pela plasticidade das formas da consciência, agora mais abstratas e, portanto, aptas a um maior gradiente de diferenciação. O segundo modo de relação, marcado pela similitude das funçôes e a identificação entre os indivíduos, era acompanhado de uma espécie de consciência geral, a qual Durkheim denomina consciência coletiva, que estaria a guiar, de uma forma ou de outra, a constituição das chamadas consciências individuais.

Não interessa aqui reconstruir propriamente o argumento de Durkheim - que, no mais, conserva toda a sua complexidade -, mas assinalar que o mestre francês, em sua tipologia inicial, lança mão de um conceito que ocupará, durante algum tempo, um papel central em sua obra: o conceito de "consciência coletiva”. Tratava-se, segundo Durkheim, daquele:
"[...] conjunto de crenças e sentimentos comuns à média dos membros de uma mesma sociedade"; conjunto que "forma um sistema determinado" e "que tem sua vida própria" (Durkheim, [1893] 1930, p. 46).

Neste primeiro momento, é bem verdade que o conceito de consciência coletiva aparece fundamentalmente ligado a um determinado modo de solidariedade (mecânica), que seria característica das sociedades com baixa divisão do trabalho. No entanto, como bem apontou Parsons, o conceito assumirá um significado algo diferente após a publicação de A Divisão do Trabalho, em 1893 (Parsons, 1937, p. 320); pois, de uma forma ou de outra, a simples complementaridade da solidariedade de tipo orgânica - típica das sociedades com intensa divisão do trabalho - parecia não ser suficiente para fornecer as bases de coesão das sociedades modernas, sendo necessário retornar, por alguma via, ao conceito de consciência coletiva.

Entretanto, a reformulação do esquema conceitual durkheimiano era resultado da percepção de um problema ainda mais profundo; pois, implicitamente, a tipologia elaborada em $A$ Divisáo do Trabalho e, particularmente, esta primeira formulação do conceito de consciência coletiva, parecia ser espreitada por um certo viés determinista da abordagem morfológica de Durkheim, o qual encontrará, posteriormente, pouco lugar em sua sociologia. O que estava em jogo em sua análise era que os diferentes regimes de solidariedade, com seus respectivos modos de relação e estruturação das consciências (individuais ou coletivas), seriam, na verdade, produto de variáveis morfológicas (tais como o volume e a densidade sociais) que estariam na base da divisão do trabalho.

Assim, a mencionada reformulação do esquema conceitual durkheimiano - que passava por uma mudança no uso do próprio conceito de consciência coletiva - resultava, num certo sentido, da recusa durkheimiana em entender a sociedade em termos estritamente morfológicos. Ela era fruto de uma percepção profunda, que seria melhor desenvolvida por Durkheim em seus trabalhos subsequentes: a de que sociedade, antes de tudo, constitui uma potência moral; que ela deve ser inspirada por ideais coletivos capazes de fornecer as coordenadas normativas e o 
referencial social das açóes. É exatamente neste sentido que a consciência coletiva não podia, de modo algum, ser concebida como uma forma de solidariedade datada ou residual. Ela era absolutamente central para a vida social, entendida, agora, como constituída inteiramente de representaçôes. (Durkheim, [1895] 1937, p. ix).

As consequências dessa mudança de percepção são notáveis e acabam por ter um impacto considerável no esquema conceitual de Durkheim. Há, nesse sentido, ao menos três ordens de mudanças que valeria destacar. A primeira delas é a de que a antiga oposiçáo entre os dois tipos de solidariedade não poderia mais se sustentar, ao menos não nos termos propostos pela tipologia inicial de Durkheim. Nesse sentido, Némedi enfatizará, por exemplo, que "após a publicação de A Divisão do Trabalho, ele [Durkheim] abandona a sua tipologia e ela não voltará a aparecer de maneira significativa em seus escritos teóricos" (Némedi, 1995, p. 83). A segunda consequência, também já mencionada, é a de que o abandono de uma morfologia determinista é acompanhado do abandono do sentido original do termo "consciência coletiva". (Lukes, 1973, p. 229-230). A terceira consequência, imediatamente ligada à anterior, é de que o próprio conceito de consciência coletiva passa a operar num registro menos rígido do que antes. Ele passa a suportar novos conteúdos náo necessariamente ligados àquelas condiçóes sociais nas quais a identidade seria simples funçáo da igualdade ou da semelhança entre as ocupaçóes. Neste sentido, o conceito de consciência coletiva passa a poder ser usado também no caso de grupos em que a identidade valorativa seria função de estruturas altamente diferenciadas. ${ }^{7}$

Até aqui, nos encontraríamos no limiar daquela inflexão supramencionada, visto que a mudança de entendimento positivo sobre o conceito de consciência coletiva precipita justamente aquele movimento no qual as representações coletivas passam ao centro do esquema conceitual durkheimiano. De certa forma, o abandono do sentido original e o afrouxamento do novo conceito coincidem com um movimento de submissão à ideia de representação. Assim, é possível argumentar que, mesmo mantendo sua importância, o conceito de consciência coletiva deixa de desempenhar papel central. Ele passa a operar em função do conceito de representação: a consciência coletiva passa a figurar, de uma maneira ou de outra, como o espaço próprio às chamadas representaçóes coletivas. Cronologicamente, seria possível situar esse movimento de inflexão naquele período que sucede imediatamente à publicação de $O$ Suicídio, em 1897 - sendo possível notar, inclusive, como ele já se antecipa nos últimos capítulos dessa obra. No ano seguinte, não por acaso, Durkheim dedicará um texto inteiro ao conceito de representação (Durkheim, 1898). A partir desse momento, como se sabe, as representaçóes coletivas passarão a constituir uma peça central no interior de seu pensamento.

\section{Esboço de uma teoria (multidimensional) das representaçōes}

Argumentamos que os potenciais multidimensionais da obra durkheimiana podem ser mais bem compreendidos à luz da passagem entre uma reflexáo preocupada com a morfologia social e uma reflexão que passa a considerar as representaçóes coletivas como peça fundamental do edifício sociológico. Nesse caso, o significado do conceito de representação deve ser compreendido frente à tentativa durkheimiana de uma superação crítica em relação a duas vertentes de pensamento: materialismo e idealismo. No caso específico da sociologia, isso significava superar a distinção entre uma concepção puramente externalista dos fenômenos sociais e uma concepção meramente internalista dos fenômenos mentais.

O termo "representação" - tal como herdado por Durkheim de seu mestre, Charles Renouvier, principal kantiano na França - parecia justamente adequado neste sentido: de certo modo, representaçáo podia ser tanto o objeto representado, como o respectivo ato de sua representação. Em verdade, o termo parece comportar, no interior da sociologia durkheimiana, duas dimensões, as quais poderíamos designar - se quisermos estabelecer uma analogia com aquilo que, mais tarde, será compreendido como signo linguístico - por "representante" e "representado". (Jones, 2000).

Insistir nessa analogia nos parece importante, embora ela não seja destituída de limitaçóes, pois, se bem compreendida, ela sinaliza para uma rearticulação 
fundamental entre os "modos de pensar e sentir" (dimensão interna da representação) e os "modos de agir” (dimensão externa da representação), que caracterizavam os antigos "fatos sociais" (Durkheim, [1895] 1937, p. 5). ${ }^{8}$ Trata-se da compreensão clara de que a dimensão exterior e material dos signos sociais poderia ser entendida, a partir daí, como "representante" e, portanto, como desempenhando uma função expressiva ou simbólica em relação a um significado social não imediatamente dado. A partir desse movimento, a teoria durkheimiana das representações abria as portas para que a sociologia pudesse investigar, não apenas as dimensóes cognitiva e mesmo valorativa das representaçóes e significados sociais, mas também o próprio caráter simbólico da vida coletiva. ${ }^{9}$ Considerações como estas, vale lembrar, não são importantes apenas para a construção de nosso argumento, mas, de modo mais geral, permitem entender os equívocos de todas aquelas leituras que identificam na sociologia durkheimiana uma empreitada incapaz de considerar quaisquer procedimentos compreensivos e que relegaria os chamados fatos sociais ao campo das objetividades estritas, cujo acesso ao sentido estaria irremediavelmente fechado. ${ }^{10}$

Para os nossos fins específicos, não basta, contudo, assinalar este deslocamento geral no interior da sociologia das representaçóes. Propomos inquirir o referencial das chamadas representaçóes - isto é, a quais entidades ou elementos elas correspondem - e, a partir daí, sua respectiva articulação à categoria do social. A considerar as diversas passagens nas quais Durkheim faz referência à questão das representaçóes, o termo parece possuir ao menos três tipos de referência: ideias, imagens e sensaçóes (Schmaus, 1994, p. 48). Um próximo passo lógico - não explicitamente executado por Durkheim, mas que nos parece pertinente a uma reconstrução adequada de seu pensamento - consiste justamente no cruzamento de cada uma dessas referências com a categoria do social, o que nos levaria a um novo campo representacional, povoado por ideias coletivas, imagens coletivas e sentimentos coletivos. ${ }^{11}$ Feita esta articulação fundamental, a sociologia parecia, então, poder estudar, de um ponto de vista científico, as elaborações sociais de pelo menos três tipos de representaçôes coletivas: conceitos, símbolos e valores.
Dito isto, gostaríamos de insistir em dois aspectos que nos parecem centrais no que concerne a sociologia das representaçóes. $\mathrm{O}$ primeiro diz respeito a uma certa autonomia entre os tipos de representação concebidos por Durkheim. No prefácio à segunda edição de As Regras do Método Sociológico, o autor diz, por exemplo:

Parece, com efeito, inadmissível que a matéria de que são feitas as representações não agiria sobre seus modos de combinação. É verdade que os psicólogos, por vezes, falam em leis de associação de ideias, como se fossem as mesmas para todas as espécies de representaçóes individuais. Mas nada é mais inverossímil do que isso: as imagens não se compóem entre si como as sensações, nem os conceitos como as imagens. Se a psicologia estivesse mais avançada, ela constataria, sem dúvida, que cada categoria de estados mentais possui leis formais que lhe são próprias. Se é assim, devemos a fortiori esperar que as leis correspondentes do pensamento social sejam específicas como esse pensamento mesmo. (Durkheim, [1895] 1937, p. xvii).

O que esse tipo de afirmação sugere, ainda que por analogia, é que as ideias coletivas, os símbolos e os sentimentos coletivos conservam entre si uma autonomia que deve marcar, respectivamente, as diferenças entre uma sociologia do conhecimento, uma sociologia dos símbolos e uma sociologia dos valores e da moralidade. A segunda característica deste tipo de encaminhamento é a de que a autonomia desses domínios parece se realizar na medida em que tais representaçôes possuem "leis formais que lhe são próprias”. Uma tal afirmação sugere, ao que parece, que a sociologia deveria trabalhar com determinados sistemas de representaçóes: sistemas de ideias, sistemas de valores e sistemas de símbolos.

Postas estas breves observaçóes, podemos ter uma imagem mais ou menos clara a respeito do projeto sociológico de Durkheim e do modo como ele encaminhava uma certa sociologia das representaçóes. O autor empreendia não apenas um novo conteúdo positivo, mas um conteúdo propriamente sociológico às teorias filosóficas e psicológicas das representaçóes. 
$\mathrm{O}$ resultado deste movimento era que caberia à sociologia, enquanto ciência positiva, investigar a dinâmica de parte dos sistemas representacionais. As representaçóes coletivas constituiriam uma nova realidade situada em um campo dotado de leis próprias, que deveria constituir um ponto de partida fundamental para toda investigação do mundo social.

Vale notar, entretanto, que o potencial deste tipo de colocação, se bem compreendido, foi não apenas enunciado, mas perseguido metodicamente por Durkheim, em sua última grande obra, As Formas Elementares da Vida Religiosa (1912). Nesse caso, encontramos uma articulação - que se expressa na própria estrutura da obra, dividida em três partes - entre uma sociologia das ideias coletivas (conceitos e crenças), uma sociologia dos sentimentos coletivos (valores sagrados e profanos) e uma sociologia das imagens coletivas, bifurcada entre o estudo das imagens espaciais (emblemas e símbolos) e o das imagens temporais (rituais e performances).

Feitas estas consideraçóes, é preciso insistir, contudo, em um ponto adicional: embora Durkheim ainda pareça se referir a diferentes tipos de representação - como se se tratasse de entidades ontologicamente distintas -, entendemos que a autonomia dos sistemas representacionais pode ser (re)lida como marca da irredutibilidade de diferentes dimensōes analíticas situadas no interior de uma teoria geral das representações. Desse modo, teríamos dimensões distintas de toda representação - dimensôes cognitiva, valorativa-afetiva, expressiva -, cujo acento marcaria a peculiaridade dos diferentes regimes representacionais: regimes de conceitos e sua respectiva articulação em crenças; regimes de valores e suas articulaçôes em normas e imperativos morais; regimes simbólicos articulados por meio de imagens temporais (performances rituais e práticas expressivas) e imagens espaciais (figuraçôes, emblemas, instrumentos depositários de sentido social). Teríamos, com Durkheim, uma teoria multidimensional das representaçóes.

A partir deste modo de releitura, encontraríamos, no âmago do pensamento durkheimiano, uma rearticulaçấo fundamental entre a dimensão ideal dos significados representacionais e a dimensão material das práticas e dos objetos sociais - a qual, até então, sempre compôs parte da chamada morfologia social.
Assim, longe de se deixar levar por uma espécie de sedução idealista, o representacionismo de Durkheim não apontaria para um sistema determinante de significados à espera de uma deposição em veículos materiais - eis a limitaçáo supramencionada em relaçáo à analogia com a linguística saussureana. Em seus estudos sobre o totemismo, o sociólogo lembrou, em diversas ocasióes, não apenas o modo como as práticas e símbolos rituais possuíam a capacidade de representar e, até mesmo, (re)criar significados (Durkheim, 1912, p. 240), mas também chamou atenção para as relaçóes entre os diversos regimes de representaçōes coletivas e a estrutura social subjacente. Neste sentido, Schmaus lembra, acertadamente, que a tipologia morfológica estabelecida nas Regras do Método, um dos primeiros textos de Durkheim, subjaz a toda a análise das Formas Elementares, possibilitando ou inviabilizando, por exemplo, a comparação das crenças totêmicas entre grupos situados em pontos diferentes da escala morfológica (Schmaus, 1994, p. 232; 237-8). Vale lembrar que nem mesmo as representaçôes cognitivas mais elementares, as categorias do pensamento, estavam alheias, segundo a perspectiva durkheimiana, a processos de remissão e correspondência em relação à materialidade dos fenômenos naturais (Schmaus, 1994, p. 76; Gomes Neto, 2018, p. 291-309).

\section{Consideraçóes finais: por uma reconexáo da tradição durkheimiana}

Compreendida da maneira aqui exposta, a abordagem representacional de Durkheim abriria, para além de um encaminhamento propriamente multidimensional, algumas possibilidades lógicas de desenvolvimento: 1) a priorização da dimensão cognitiva das representaçóes e, portanto, dos sistemas conceituais e classificatórios em relação aos valores e práticas coletivas; 2) a priorização da dimensão valorativa-afetiva e, consequentemente, a dos sistemas normativos em detrimento dos sistemas de conceitos e práticas; e 3) a priorizaçáo da dimensão expressiva e material das representaçóes, realizada seja pela remissão das dimensōes cognitivas e valorativas à das práticas e performances rituais, seja pela sua remissáo à materialidade dos signos. Nesse último 
caso, é claro, nos encontraríamos no limiar de um retorno à materialidade do mundo social e, portanto, às portas de sua morfologia.

Nossa hipótese de (re)leitura é a de que essas possibilidades lógicas não apenas estavam dadas virtualmente no interior do esquema conceitual durkheimiano, como parecem ter encontrado um desenvolvimento fértil na teoria social do século XX. Acreditamos que é nesta chave que podemos compreender, respectivamente - sem uma necessária contradição ou quebra de coerência -, a alocação de figuras aparentemente distantes, como Lévi-Strauss, Parsons, Goffman e outros, no interior da tradição durkheimiana.

Lévi-Strauss, como se sabe, pareceu levar adiante as reflexôes da tradição durkheimiana, privilegiando não propriamente os valores e práticas sociais, mas os padrôes simbólicos e, sobretudo, o pensamento classificatório e os chamados operadores lógicos inconscientes, capazes de fornecer as estruturas formais do espírito e da cultura, mediante possibilidades lógicas de combinatória e interditos de transposição representacionais. Por essa via, aliás, o cognitivismo da tradição durkheimiana reencontraria um antigo conhecido, o transcendentalismo kantiano.

Goffman, como insistimos, pareceu levar a cabo não apenas as reflexóes de Durkheim quanto à efervescência coletiva, mas, sobretudo, sua teoria dos rituais sociais, desenvolvida no contexto do totemismo. Nesse caso, os antigos rituais totêmicos seriam substituídos pelos chamados rituais da vida cotidiana, a partir do que Goffman pôde elaborar uma sociologia dramatúrgica/performática capaz de privilegiar, como objeto de análise, uma certa gramática das interaçóes.

Parsons, embora talvez o mais fiel ao espírito durkheimiano da multidimensionalidade, pareceu também privilegiar, por vezes, no interior de sua teoria da ação, os padróes valorativos e normativos de orientação. Assim, vale notar que não só sua teoria da ação pôde ser compreendida como remetendo a um certo tipo de "estruturalismo voluntarista", como o próprio funcionalismo parsoniano pôde ancorar as reflexóes morfológicas de Durkheim em um sistema representacional eminentemente valorativo, compreendido como ocupando o topo de sua hierarquia cibernética.

Para cada um destes desdobramentos, provenientes de um esquema geral centrado no conceito de representação, seria possível projetar, é claro, um tipo de contraparte tendendo à reconexão com a morfologia, com seus signos materiais, suas alocaçóes funcionais e suas experiências fundamentais. Embora não tenham se fundado em uma apreciação adequada da última fase do pensamento durkheimiano - como Lévi-Strauss, Goffman e Parsons -, é possível insistir que autores como Radcliffe-Brown, Merton e mesmo Garfinkel, sejam interpretados nesse direção, caso se queira alocá-los ainda no interior das malhas da matriz durkheimiana.

A partir deste conjunto de considerações, não pretendemos esgotar, evidentemente, a "tradição durkheimiana”, ou mesmo desvendá-la em seus pormenores, mas apenas esboçar um caminho possível para a sua reconstrução futura e que parece acenar com a possibilidade de um ganho significativo de inteligibilidade. Isto porque, é tarefa de toda reconstrução fornecer os vínculos significativos, as possibilidades de encaminhamento e os limites de articulação. Eis o que a consideração de uma teoria multidimensional das representaçôes, assim como sua respectiva (re)articulação em relação a uma reflexão da morfologia, parece nos permitir fazer.

\section{Notas}

1 Quando falamos em uma "tradição durkheimiana”, nos referimos a algo bem mais amplo do que a chamada "escola durkheimiana", organizada em torno da L'année Sociologique. Trata-se, aqui, daquele conjunto de herdeiros capazes de compor um quadro de família a longo prazo, no interior da história da sociologia. Neste caso, é claro, nos referimos a autores cujo alegado impacto, tal como seu respectivo lugar histórico, devem ser justificados na exata medida em que ultrapassam a posição de simples continuadores; isto é, na medida em que promovem algum tipo de revisão, rearticulação e renovação criativa das ideias de Durkheim: seja por meio da incorporação de outras contribuiçóes teóricas mediante sínteses mais amplas, seja por meio da sua aplicação a fenômenos inicialmente imprevistos com vistas ao reordenamento e à expansão de seu esquema conceitual inicial. 
2 Todas as citaçóes foram traduzidas pelo autor deste artigo.

3 Embora tenha sido, por vezes, associado ao interacionismo simbólico, Goffman nunca se considerou parte desse movimento - mencionando-o pouquíssimas vezes e, quase sempre, de maneira muito crítica (ver: Collins, [1991] 2009, p. 234). Parte dessa ressalva parece poder ser atribuída ao fato de que sua leitura da obra de Mead - sua outra grande inspiração entre os teóricos sociais clássicos, ao lado de Durkheim, e também a grande referência em comum com os interacionistas - foi bastante distinta e, por vezes, até mesmo oposta, em relação à leitura propagada por Blumer, nos anos 1940 e 1950. Em verdade, a percepçáo da obra de Goffman - principalmente aquela escrita até meados dos anos de 1960 -, como herdeira do pensamento durkheimiano, tem sido defendida por uma série de comentadores amplamente familiarizados com o corpus durkheimiano, tais como o próprio Randall Collins ([1991] 2009), Anne Rawls (2003) e Frederic Keck (2012).

4 Destacamos, aqui, alguns exemplos: Besnard (1979), Clark (1973), Heilbron (1985), Kando (1976), Lévi-Strauss (1945), Marcel (2001), Massella (2009).

5 É preciso notar que, nos últimos vinte ou trinta anos, salvo algumas exceçóes, a maioria dos comentadores mais autorizados da obra de Durkheim parece sustentar este tipo de posição. É o caso, por exemplo, dos já mencionados Warren Schmaus (1994), Anne Rawls (1996) e Susan Stedman Jones (2001). Para um breve balanço desse tipo de controvérsia, ver: Schmaus (1994, p. 12-17); Rawls (1996, p. 468-477).

6 A centralidade do conceito é destacada por uma lista tão grande de comentadores, que seria até mesmo difícil mencionar todos. Para nossos fins, parece suficiente lembrar que, em 2000, o conceito foi alvo de um volume inteiro, organizado por Pickering, que conta com textos de comentadores renomados, como David Bloor, Dénes Némedi, Giovanni Paoletti, Susan Stedman Jones e Warren Schmaus, além de dois textos do próprio Pickering.

7 Parsons lembra que as análises desenvolvidas por Durkheim, a respeito do suicídio altruísta, são ilustrativas nesse sentido. Nas sociedades modernas, esse tipo de suicídio - marcado pelos imperativos da consciência coletiva - seria típico de grupos militares. Mas, o exército, como se sabe, constituiria um grupo altamente diferenciado e hierarquizado em termos de patentes e funçôes. O conteúdo da consciência coletiva seria, nesse caso, o da disciplina e o da hierarquia, apreendidas no interior de um grupo diferenciado. Entretanto, ao assinalar esse ponto, Durkheim mostraria como a consciência coletiva poderia estender-se a grupos nos quais a identidade não seria função necessária da igualdade de ocupações, mas de uma diferenciação funcional. (Parsons, 1937, p. 328-30).

8 Vale notar que o termo "representação" vai, aos poucos, assumindo o antigo conteúdo dos chamados "fatos sociais"; isto é, os "modos de agir, pensar e sentir". A substituiçấo de nomenclatura no interior do desenvolvimento intelectual de Durkheim não é aleatória. A palavra "fato" remetia ao aspecto exterior da realidade social e, de certo modo, servia aos propósitos iniciais de demarcação da sociologia, enquanto ciência capaz de conhecimento objetivo. Entretanto, a partir de fins dos anos 1890, quando Durkheim passa a se interessar pelos processos de subjetivação da vida social - o que fica evidenciado em suas investigaçóes sobre a educação, a internalização de padrôes morais e simbólicos e, por fim, em seu interesse nas práticas rituais e nos fenômenos de efervescência coletiva -, a palavra "fato" torna-se demasiadamente inadequada, sendo substituída por "representação", cuja ambiguidade semântica parece ter sido compreendida como mais adequada à sociologia.

9 É preciso assinalar que a dimensão simbólica dos fatos sociais náo havia passado despercebida ao jovem Durkheim. Cabe lembrar que, em Da Divisão do Trabalho Social, sua tese de doutorado, Durkheim já assinalara, por exemplo, o elemento simbólico da sanção, no caso dos direitos penais (Durkheim, [1893] 1930, p. 64-70). Entretanto, ao que parece, é somente a partir de sua inflexão em direção a uma sociologia das representaçôes, que Durkheim passa a poder desenvolver essa percepçáo fundamental em toda a sua amplitude e complexidade.

10 Schmaus (1994), por exemplo, desenvolveu, num trabalho notável, a tentativa de compatibilizar, no interior da sociologia de Durkheim, as explicaçóes dos chamados fatos sociais e a questáo do sentido.

11 Nos distanciamos, aqui, da leitura de comentadores, como Schmaus (1994, p. 48), que tendem a associar o campo das representaçóes coletivas ao das ideias, e o das representaçôes individuais ao das imagens e sensaçôes.

\section{AGRADECIMENTOS}

Agradeço à Raquel Weiss e aos colegas do Centro Brasileiro de Estudos Durkheimianos, com quem discuti as ideias desse artigo nos últimos anos. 


\section{BIBLIOGRAFIA:}

ALEXANDER, Jeffrey C. (1987), Twenty Lectures: Sociological Theory Since World War II, Nova York, Columbia University Press.

ALEXANDER, Jeffrey C. (org.). (1988a), Durkheimian Sociology: Cultural Studies, Cambridge, Cambridge University Press.

ALEXANDER, Jeffrey C. (1988b), "Introduction: Durkheimian Sociology and Cultural Studies Today", in J. C. Alexander (org.), Durkheimian Sociology: Cultural Studies, Cambridge, Cambridge University Press.

ALEXANDER, Jeffrey C. (2005), “The inner development of Durkheim's sociological theory: from early writings to maturity", in J. C. Alexander \& P. Smith (org.), The Cambridge Companion to Durkheim, Nova York, Cambridge University Press.

ALEXANDER, Jeffrey \& SMITH, Philip. (org.). (2005), The Cambridge Companion to Durkheim. Cambridge, Cambridge University Press.

BESNARD, Philippe. (1979), "La formation de l'équipe de l'Année sociologique". Revue française de sociologie, 20, 1: 7-31.

COLLINS, Randall. ([1991] 2009), Quatro Tradiçôes Sociológicas. Tradução de Raquel Weiss. Petrópolis, Vozes.

COLLINS, Randall. (2004), Interaction Ritual Chains. Princeton, Princeton University Press.

COLLINS, Randall. (2005), "The Durkheimian movement in France and in world sociology", in J. C. Alexander \& P. Smith (org.), The Cambridge Companion to Durkheim, Nova York, Cambridge University Press.

DURKHEIM, Émile. ([1893] 1930), De la Division du Travail Social. 2a edição, Paris, PUF.

DURKHEIM, Émile. ([1895] 1937), Les Règles de la méthode sociologique. 2a edição, Paris, PUF.

DURKHEIM, Émile. ([1898] 1996), "Représentations individuelles et représentations collectives", Sociologie et Philosophie, Paris, PUF.

DURKHEIM, Émile. (1912), Les Formes Élémentaires de la Vie Religieuse: le système totémique en Australie, Paris, Alcan.
DURKHEIM, Émile. ([1912] 1996), As Formas Elementares da Vida Religiosa. Tradução de Paulo Neves. São Paulo, Martins Fontes.

DURKHEIM, Émile. ([1914] 1970), "Le Dualisme de la nature humaine et ses conditions sociales", La Science Sociale et l'Action, Paris, PUF.

DURKHEIM, Émile. ([1913-4] 1955), Pragmatisme et Sociologie, Paris, J.Vrin.

GARFINKEL, Harold. (2002), Ethnomethodology's Program: Working Out Durkheim's Aphorism, Boulder, Colorado, Rowman and Littlefield.

GOFFMAN, Erving. ([1959] 1975), A Representação do Eu na Vida Cotidiana. Tradução de Maria Célia Santos Raposo. Petrópolis, Vozes.

GOFFMAN, Erving. ([1967] 2011), Ritual de Interação. Tradução de Fábio Rodrigues Ribeiro da Silva. Petrópolis, Vozes.

GOFFMAN, Erving. (1971), Relations in Public: microstudies of the public order, Nova York, Basic Books.

GOMES NETO, Jayme. (2015), Durkheim, Kant $e$ as Categorias do Pensamento. Dissertação de Mestrado. Faculdade de Filosofia, Letras e Ciências Humanas, USP, São Paulo.

GOMES NETO, Jayme. (2018), "As Categorias Sociológicas do Pensamento: Durkheim, Herdeiro Crítico de Kant”, in J. Gomes Neto; A. Magnelli; R. Weiss (orgs.), Durkheim, Apesar do Século: Novas Interpretaçóes entre Sociologia e Filosofia, São Paulo, Annablume.

HEILBRON, Johan. (1985), "Les métamorphoses du durkheimisme". Revue française de sociologie, 26, 2: 203-237.

HILBERT, Richard A. (1991), "Ethnomethodological Recovery of Durkheim”. Sociological Perspectives, 34, 3: 337-357.

JONES, Susan S. (2000), "Representation in Durkheim's masters: Kant and Renouvier", in W. S. F. Pickering (org.), Durkheim and Representation, Londres, Routledge.

JONES, Susan S. (2001), Durkheim Reconsidered. Cambridge, Polity Press.

KANDO, Thomas M. (1974), "L'Année Sociologique: From Durkheim to Today". The Pacific Sociological Review, 19, 2: 147-174. 
KECK, Frédéric. (2012), "Goffman, Durkheim et les rites de la vie quotidienne". Archives de Philosophie, 75, 3: 471-492.

LÉVI-STRAUSS, Claude. ([1945] 1995), "French Sociology", in P. Hamilton (org.), Emile Durkheim: Critical Assessments, Londres, Routledge.

LÉVI-STRAUSS, Claude. ([1949] 1982), As Estruturas Elementares do Parentesco. Tradução de Mario Ferreira. Petrópolis, Vozes.

LÉVI-STRAUSS, Claude. ([1962] 1975), Totemismo Hoje. Tradução de Malcolm Bruce Corrie. Petrópolis, Vozes.

LUKES, Steven. ([1973] 1985), Emile Durkheim: His Life and Work: a Historical and Critical Study, Stanford, Califórnia, Stanford University Press.

MARCEL, Jean-Christophe. (2001), Le durkheimisme dans l'entre deux Guerres, Paris, PUF.

MARYANSKI, Alexandra \& TURNER, Jonathan H. (1991), "The Offspring of Functionalism: French and British Structuralism”. Sociological Theory, 9, 1: 106-115.

MASSELLA, Alexandre. B. (2009), "Leituras da Escola Durkheimiana", in A. Massella et al. (org.), Durkheim: 150 anos, Belo Horizonte, Argvmentvm.

MERTON, Robert K. (1934), “Durkheim's Division of Labour in Society". American Journal of Sociology, 40, 3: 319-28.

MERTON, Robert K. ([1949] 1968), Social Theory and Social Structure, Nova York, The Free Press.

MERTON, Robert K. (1959), "Conformity, Deviation, and Opportunity-Structures". American Sociological Review, 24: 178-189.

MERTON, Robert K. (1994), "Durkheim's Division of Labour in Society: A Sexagenarian Postscript". Sociological Forum, 9, 1: 27-36.

MURDOCK, George P. (1953), “Social Structure”, in S. Tax et al. (org.) An Appraisal of Anthropology Today, Chicago, University of Chicago.

NÉMEDI, Dénes. (2000), "Change in Ideas: Collective Consciousness, Morphology, and Collective Representations", in W. Pickering (org.), Durkheim and Representation, Londres, Routledge.
PARSONS, Talcott. ([1937] 1968), The Structure of Social Action, Nova York, Free Press.

PARSONS, Talcott. (1960), "Durkheim's contribution to the Theory of Integration of Social Systems", in K. Wolff (org.), Emile Durkheim, 1958-1917, Columbus, Ohio State University.

PARSONS, Talcott. (1978), Action Theory and Human Condition, Nova York, Free Press.

PICKERING, William S. F. (org.). (2000), Durkheim and Representations, Londres, Routledge.

RADCLIFFE-BROWN, Alfred R.(1952), Structure and Function in Primitive Society: Essays and Addresses, Glencoe, The Free Press.

RAWLS, Anne Warfield. (1996), “Durkheim's Epistemology: The Neglected Argument”. American Journal of Sociology, 102, 2: 430-482.

RAWLS, Anne Warfield. (2000), “Durkheim's Treatment of Practice". The Classical Journal of Sociology, 1, 1: 33-68.

RAWLS, Anne Warfield. (2003), “Orders of Interaction and Intelligibility: Intersections between Goffman and Garfinkel by Way of Durkheim”, in J. A. Treviño (org.), Goffman's Legacy, Maryland, Rowman \& Litnefield.

RAWLS, Anne Warfield. (2004), Epistemology and Practice: Durkheim's the Elementary Forms of Religious Life, Nova York, Cambridge University Press.

SCHMAUS, Warren. (1994), Durkheim's Philosophy of Science and the Sociology of Knowledge: Creating an Intellectual Niche, Chicago, The University of Chicago Press.

SMELSER, Neil \& WARNER, Stephen R. (1976), Sociological Theory: Historical and Formal, Nova Jersey, General Learning Press.

TIRYAKIAN, Edward A. (2000), "Parsons's Emergent Durkheims". Sociological Theory, 18, 1: 60-83.

TREVIÑO, A. Javier. (2003), "Introduction: Erving Goffman and the Interaction Order", in J. A. Treviño, (org.), Goffman 's Legacy, Maryland, Rowman \& Litnefield. 


\section{POR UMA RECONSTRUÇÁO DA TRADIÇÁO DURKHEIMIANA}

\section{Jayme Gomes Neto}

Palavras-chave: Durkheim; Representaçóes Coletivas; Tradição Durkheimiana; Lévi-Strauss; Parsons; Goffman.

O presente texto busca debruçar-se sobre a chamada “tradição durkheimiana”, até então associada a um conjunto mais ou menos disperso de desdobramentos intelectuais, a fim de responder à seguinte pergunta: será possível encontrar, por trás dos desenvolvimentos teóricos aparentemente contraditórios de autores como Lévi-Strauss, Parsons, Goffman, e outros pretensos herdeiros do legado durkheimiano, algum tipo de esquema conceitual dotado de possibilidades lógicas de desenvolvimento a tal ponto abertas, que pudéssemos ainda alocá-los no interior de uma herança intelectual dotada de coerência e unidade? Um problema desse tipo remonta, é claro, não apenas à identidade da tradição, mas a uma possível unidade no interior da obra durkheimiana. Nossa hipótese de trabalho é de que a teoria das representaçóes coletivas, tal como formulada pelo sociólogo francês em seus textos tardios, poderia fornecer uma possível resolução para essas questôes.

\section{FOR A RECONSTRUCTION OF THE DURKHEIMIAN TRADITION}

\section{Jayme Gomes Neto}

Keywords: Durkheim; Collective Representations; Durkheimian tradition; Lévi-Strauss; Parsons; Goffman.

\begin{abstract}
The present text seeks to address the so-called "Durkheimian tradition", until then associated with a more or less scattered set of intellectual developments in order to answer the following question: would it be possible to find, behind the apparently contradictory theoretical developments by authors such as Lévi-Strauss, Parsons, Goffman, and other would-be heirs of the Durkheimian legacy, some kind of conceptual scheme endowed with logical development possibilities so open that we could still allocate them within a coherent intellectual heritage endowed with coherence and unity? Such a problem goes back, of course, not only to the identity of the tradition but to a possible unity within the Durkheimian work. Our working hypothesis is that the theory of collective representations, as formulated by the French sociologist in his late texts, could provide a possible resolution to these issues.
\end{abstract}

\section{POUR UNE RECONSTRUCTION \\ DE LA TRADITION DURKHEIMIENNE}

\section{Jayme Gomes Neto}

Mots-clés: Durkheim; représentations collectives; tradition durkheimienne; Lévi-Strauss; Parsons; Goffman.

Le présent travail analyse ladite « tradition durkheimienne ", jusqu'alors associée à un ensemble plus ou moins épars de dédoublements intellectuels, afin de répondre à la question suivante: derrière les développements théoriques apparemment contradictoires d'auteurs comme Lévi-Strauss, Parsons, Goffman et d'autres prétendus héritiers du durkheimisme, existe-t-il un schéma conceptuel aux possibilités logiques de développement suffisantes pour parler d'un héritage intellectuel cohérent et unitaire? Un tel problème ne concerne pas seulement l'identité de la tradition, il renvoie aussi à la question de l'unité au sein de l'œuvre de Durkheim. Nous posons l'hypothèse que la théorie des représentations collectives, telle que formulée par le sociologue français dans ses derniers textes, pourrait apporter une réponse possible à ces interrogations. 